\title{
Power Relationships within the UK Police Service: Towards Enhanced Female Career Progression
}

\author{
Janet Astley, Leeds Beckett University
}

\begin{abstract}
This paper aims to consider the potential for using power relationships positively to enhance the career progression of senior female police officers by the implementation of sustainable and cost-effective HRD interventions. Women have long been under-represented at senior ranks in the UK service due to a plethora of reasons. Understanding those reasons and embedding effective opportunities for personal development, such as mentoring and networking are considered. The combination of the efficient use of the personal development review system alongside addressing issues in relation to both public and internal perceptions of women's' capability and potential by adopting good HRM practices and policies are likely to increase female representation and reduce the attrition of talent. The use of existing senior officers, regardless of gender, to act as coach/mentors alongside recognising the value of internal and national networks may reap benefits for the service increasing its diversity and shifting the organisational culture to becoming more representative of modern society.
\end{abstract}

Key Words: gender, policing, diversity, career development

\section{Introduction}

This paper reports on a qualitative research study examining the under-representation of females in senior leadership roles in UK policing. Its aim is to offer insight as to how women can be encouraged to rise through the ranks and offers solutions to policy makers to enable a more gender diverse police service. The paper explores the significance of power relationships between senior ranking officers and (female) subordinates and their impact upon women's career progression within the police service. These relationships are significant as the endorsement of individuals' suitability for promotion is based upon them. Gendered constructions require women to be given 'permission' to progress their careers affecting relationships both positively and negatively. Thirty-five semistructured, one to one life-history narrative interviews were conducted. Evidence indicates that male mentors' protégés fare better in the promotion stakes. Positive power relationships must be established in order to ensure consistency, parity and fairness in promotion boards, enabling women to achieve the highest ranks. The paper unfolds as follows. First the research context is explained in relation to the problem of under-representation of women at senior levels within the UK police force. The approach adopted for the research is then outlined before the main findings to emerge are discussed. A concluding discussion as regards practice implications completes the paper.

\section{Context}

This paper stems from a larger study conducted in 2011 that was the first to ask the question why do so few women achieve the higher ranks in policing? Earlier and subsequent studies 
have considered various aspects of gender and leadership inequality within the service, but no other study has directly asked the reasons why females fail to reach senior ranks in policing or suggested initiatives to remedy the situation. This paper seeks to address some aspects of the issue offering cost effective solutions that can be implemented with relative ease. The influence of power relationships is critical to the success or detriment of female career progression and this paper seeks to identify causes and solutions to gender inequality in UK policing.

Although there has been improvement in the representation of women, the numbers of high ranking women within UK policing remain limited. The latest Home Office Statistical Bulletin indicates a slight decrease of overall promotion across the ranks.

Of the 3,255 police officers promoted in the 43 police forces in 2016/17, 876 were female, which accounted for $27 \%$ of all officer promotions (compared with $29 \%$ of female officers). This was an increase on the year before, which saw 442 female officers promoted, accounting for $24 \%$ of all officer promotions (Hargreaves, Husband \& Linehan, 2017, p. 32).

The 2018 bulletin indicates significant improvement in that the highest ever recorded number of female officers (30\%) are currently in service with $34 \%$ of women joining the service and $24 \%$ leaving. Therefore the attrition rate of female officers must be of concern to the service due to the investment required in recruiting, training and deployment of officers. (Hargreaves, Husband \& Linehan, 2018). The majority of females remain at the lower ranks of Police Constable to Inspector with few reaching Chief Officer status and this paper seeks to ascertain how representation of females at more senior ranks might be achieved.

Power relationships between senior ranking officers and their subordinates have a significant impact upon opportunities for career progression within the police service of England, Wales and Northern Ireland, particularly for women. The relationships between officers and their immediate commanders is significant and relevant, as the endorsement of an individuals' suitability for promotion is based upon such power relationships.

Muller-Hendryk (2019) comments that gender inequality is not exclusive to policing and occurs across a range of organizations with double standards being applied to progression opportunities for women who face increased challenges than their male counterparts. Organizational culture has a significant impact upon maintaining the status quo, with both male and female managers' behaviours impacting upon female career progression. This paper is set in the context of policing and so draws primarily upon police related literature.

Cordano, Scherer and Owen (2002) and Dick and Jankowicz (2001) refer to the issues relating to culture and leadership which stem from the seminal policing study by Martin (1979). Martin identified the issues in relation to gender and policing and her original work. However, it seems that despite some improvement of opportunity for women to progress their careers in policing there remains, after 20 years of research, an impasse in the expectation of gender equality at all ranks within the service.

Past studies into policing have tended to concentrate on the masculine and patriarchal perspectives in relation to power relationships. Command and control are rarely recognized as female traits, yet essential to successful policing, with the public concept of crime and criminology remaining masculine in nature. Campbell (2003) and Astley (2011) challenge the traditional view that women are subordinate and oppressed in male-dominated organizations arguing that women accept the need to adapt to particular situations and therefore become architects of their own 
destiny by positively manipulating opportunities that arise. Assertive, dominant, and even aggressive behaviour is considered negative when attributed to women in leadership positions (Muller-Hendryk, 2019), yet these traits may need to be adopted in order to appear competent in policing. Women's more natural skills, communication, listening, team-working and nurturing are also valued and are becoming more accepted as the service begins to culturally shift.

Silvestri and Crowther Dowey (2008, p. 177) comment that "a rank governed progression system has particularly damning consequences for women wanting to progress" especially due to the length of a police officer's career, spanning up to 30 years' service, but also, the often interrupted nature of women's careers due to biological or familial commitments frequently results in them being perceived by others in the service, both male and female, as lacking commitment 'to the job'. Police work requires officers to build evidence of a long and incremental career path providing confirmation of their suitability for promotion based upon experience and, more importantly, sponsorship by a senior mentor or supporter.

The same authors suggest that barriers to equality within policing is due to the existing and continuing gender imbalance; the dominance of males in senior positions controlling the power relationships that result in promotion. They comment that "a preponderance of men in influential and powerful positions, is still an obstacle to equality" (p. 153). They identify the three faces of power, the conduct of decision makers, the conflicts between actors and the significance of issues. These manifest as organizational culture combined with the decision maker's position, gender and the resultant conflict of interests which links to the ideologies of heterosexism and masculinity, which impacts negatively upon the experiences of aspiring female officers.

Gendered constructions appear to require women to be given support or 'permission' to progress their careers (Osterlinde \& Haake, 2010). Gender can also affect relationships as evidence indicates that male mentors' protégés frequently fare better in the promotion stakes (Ramaswami et al. 2010). However, women tend to seek out other women as mentors (Sealy \& Sing, 2010), particularly within policing, although senior ranking females may not always be in a position to endorse the career paths of those women who seek to follow in their footsteps, for a variety of reasons. The use and abuse of such power relationships, regardless of the gender mix, may significantly impact upon an individual's career progression with examples of both male and female misogyny (Mavin, 2006a, 2006b).

There are inter-linking connections between power and gender in policing. In terms of navigating their way through the ranks O'Connor (2001) suggests that women's concept of power lies in their ability to make lateral rather than upward career moves due to a desire to retain control over their own destiny. She implies that many women perceive their ability to achieve significant rank as limited, remaining content within the lower ranks. This is frequently a direct life style choice. For those who do seek promotion, the issue relating to negative stereotyping as their power and rank increases results in them being perceived as "troublesome, unreasonable, unnecessarily aggressive and even unfathomable" Olsson (2000, p. 300). McGregor (2000) comments that women are frequently discriminated against, misrepresented and often denied their successes as their seniority increases resulting in ridicule of their achievements by others. Mavin (2006a, 2006b) identifies that women in male-dominated professions face both male and female misogyny resulting in mistrust. For some women there is a notion of betrayal to their gender due to an inability of other aspiring women to relate to senior women, or the lack of opportunity for those who have achieved rank to assist in the transition of aspiring others to 
higher status. Frequently the inability to assist relates to a variety of (work related) reasons, not a lack of desire. The most significant obstacle is the excessive workload of all senior ranking officers. This lack of ability to assist others' progression may result in them being perceived as "Queen Bees" Mavin (2008). Mavin et al. (2014) identify the prevalence of intra-gender micro-aggression which further exacerbates the situation successful and high ranking females experience. Therefore, it seems that only the most determined individuals who have strong support mechanisms, particularly in the shape of a champion or mentor are likely to succeed in gaining rank.

\section{The Research: Methodology}

Policing is sensitive in nature so to establish trust and confidence in the research process no individual or force was identified. 35 In-depth, life history interviews with senior ranking female officers enabled the collection of rich and insightful data from eight forces across the UK (excluding Scotland). The justification for only interviewing female officers was to gain unique insight into females' perspectives of promotion opportunities within the service at middle and senior manager levels.

\begin{tabular}{lr}
\hline \multicolumn{2}{c}{ Rank profile of one to one in-depth interview subjects } \\
\hline Inspector & 3 \\
Chief Inspector & 14 \\
Detective Chief Inspector & 4 \\
Superintendent & 10 \\
Detective Superintendent & 2 \\
Chief Superintendent & 0 \\
Association of Chief Police Officers & 2 \\
Total & $\mathbf{3 5}$ \\
\hline
\end{tabular}

Table 1: Rank profile of one to one in-depth interview subjects

Source: Astley (2011, p. 169)

Each semi-structured interview lasted at least one hour but no more than two. All were digitally recorded, transcribed and coded identifying five discourses. Kitzinger (2000) suggests that the use of specific language and the hidden meanings within it, including the pauses, sighs and other non-verbal communications need to be interpreted and placed in context with the research subject's position, power status and position within the organization. Stokoe and Smithson (2001) agree that there is a definite place for conversation analysis in feminist research but warn that an understanding of the specific organizational culture is required to be able to interpret the context and language. The author, as a former 'insider' to the police service was able to interpret the unique language, rites, customs, practices and rituals without intrusive exploration of them, which may have resulted in mistrust. This enabled honest and open conversation. Dhunpath (2000), Sandino (2007) both extoll the virtues of such an approach commenting upon the deep insight into real-life experiences capturing emotions and feeling associated with particular events. Musson (2006) comments that life-history interviews are particularly relevant when studying organizations as it indicates the unique culture and sub-cultures that exist within. 
Mellick and Fleming (2010) note the tensions between using life-history interviews and the dilemma relating to the ethics of disclosure, particularly in relation to studying elites or high profile individuals. In order to ensure that participants were enabled to offer authentic accounts of their experiences they were assured of anonymity by non-divulgence of the force, rank or name, thus ensuring no 'harm' would occur. Each participant agreed to participate on this basis with opportunity to withdraw at any point with no violation of individual privacy. The honesty and openness of the conversations was unquestionable especially when the participants felt that their experiences might prove beneficial for future serving female officers.

\section{The Research: Summative Findings}

The interviews first sought to discuss the origins of the women's careers, from which five key discourses in relation to difference, performance and development, networking, family and flexibility and queen bees and bitches were identified. Within each of the discourses there are elements of power relationships with the most significant ones lying within performance and developing, networking and queen bees and bitches. This paper focuses upon the latter two discourses with each exploring how factors within them affected career progression. Some of these linked to cultural and social differences, financial constraints and lack of opportunity to study due to work/life balance and other commitments. Others related to power relationships that influenced performance, networking and the influences of powerful women. This paper focuses upon power relationships and how these might be used positively to influence women to pursue their careers by engaging in activities that have assisted the careers of women in other sectors of industry and learning from the wider realms of HRD.

\section{Performance}

Wodak (1997) suggests that individuals socially influence their existence by linking power relations to events. Metcalfe (2008) comments that the links between gender and power impacts upon performance "creating conditions where a reflexive approach to professional development will become impossible". (p. 453). Issues that affect the lower ranks, shift working and child care dissipate at the higher ranks particularly in relation to greater flexible working conditions enabling them to accommodate some of these domestic issues that negatively impacts at the lower ranks. There is a distinct chasm between Chief Officer ranks and those below, with women frequently finding the leap to the most senior ranks prohibitive due to a variety of factors, but predominantly lifestyle oriented. Transactional issues, such as age, length of service and family responsibility affect early career officers, but the necessity to engage in strong and powerful relationships with others affects their career trajectories and aspiration to senior ranks.

One superintendent commented upon what she termed 'immovable events' that related to family activity and the associated powerful feeling of guilt if such an event was missed. These include parent's evenings, school sports days, birthdays and anniversaries. Several others commented upon the power of women performing effectively serving as beacons for others to emulate by providing effective role modelling. There was evidence of admiration for those who appear to balance the need of family and working life.

Where the conversation turned to role mentors, competition and secondments along with the national assessment centre programme for senior officers, by which means they might achieve 
the Chief Officer ranks, these issues appeared to become more problematic. The aforementioned leap across the chasm to Chief Officer role at this point becomes unachievable through choice, as women are reluctant to sacrifice everything for the job. The increased workload along with shifting emphasis to a more strategic and political role is unattractive alongside the necessity to become mobile. For many women the emphasis of value is placed upon safety, security, quality home life and a degree of work life balance which causes them to deselect themselves from the promotion process. Many women expressed that uprooting family for their personal career was a sacrifice too far resulting in a direct choice between career and quality of life. The sacrifices made by women who achieve senior ranks appears to be, for the majority, too great. The two Chief Officers who participated in the study referred to their career as a 'battle' endorsing Olsson's (2000) view that women need Amazonian strength to achieve high status. Those who opt out of the promotion race expressed pity for male officers who feel driven to achieve high rank due to their perceived status as dominant males endorsing the societal view that men will sacrifice everything for a career.

One officer commented:

I think a lot of women emulate their male counterparts, think they have got to be like male managers. They are often feminine in appearance, but I think that femininity belies a very masculine style of leadership. They are bullies and hard, prickly and treat people in an awful way. They are male characteristics.

From this comment it appears that the adoption of male traits is perceived as an endorsement of the male power perspective. Women who exhibit such traits are disliked by both males and females and considered to be manipulative and dangerous reflecting Mavin's (2006b) notion of female misogyny.

There is no doubt that performance identifies traits that are recognized by Butler (2004) and Collinson (2003) as gendered, with the association of exceptional performance as 'strong' or 'hard'. Highly competitive workplaces are frequently associated with gendered activities such as long-hours culture, mobility and commitment to the corporate identity. This is particularly prevalent in policing which frequently debars women and older males from progressing their careers due to such practices. The concept of powerful behaviours and power dressing is highlighted as one officer comments:

I found that I had to adapt significantly to suit where I was working as an Inspector posted to tactical firearms. I had to become aggressive in my management style. I felt I had to put on a different suit to go to work. It's about survival, but you must never show your vulnerability. I would go into briefings feeling physically sick.

One officer recounted that previously, a senior ranking male officer offered to endorse her aspirational career moves by proffering sexual favours, despite her being heavily pregnant at the time. Her refusal, she felt, negatively affected her future career prospects. She considered that the incident impeded her opportunity to progress at promotion boards up until his retirement from the service - his negative influence appearing to be extensive in marginalizing this officer in relation to a gender/power abusive encounter.

The issue of personal self-confidence and self-efficacy appears significant and important. Women appear to need 'permission' to engage in promotion and career progression. One officer commented: 
Confidence - I think it's a female thing. I find that women tend to need a little shove; you need permission to go for the next one (rank). Chief Officer Mentors are important. Women won't give themselves permission until they are $110 \%$. Men have better self-belief"

Female officers use words that relate to their integrity, such as 'authentic' and 'genuine' when relating their achievements. Many expressed a preference of having access to a senior, female mentor. One officer commented:

Overwhelmingly having a female role model is good. I think what might be useful is if female officers had a female officer of a higher rank. It gives you a kick up the bum sometimes.

Limited access to mentors is problematic. The demand for mentors exceeds supply regardless of gender. Mentors are frequently overburdened by their workload preventing them from fulfilling a meaningful and supportive role. As one officer pointed out:

In recent years one of the Assistant Chief Constables (ACCs) has offered to be a mentor but often cancels. Unless you are a really determined individual or on HPDS (High Potential Development Scheme) you get little support.

The development of a national or inter-agency approach as suggested by Mains and MacLean (2017) may contribute to reducing the burden of mentoring within individual forces providing access to this powerful method of career development. Successful promotion appears to lie in the recognition and championing by an influential senior ranking officer that will endorse a candidate's suitability for promotion to the next rank. Without such access the pool of talent, regardless of gender, remains latent, with females more likely to be unsuccessful at sourcing a mentor due to their inability to break into the social networks dominated by senior ranking male officers within the service.

Opportunistic events sometimes enable the determined individual to progress. These women have to undertake difficult jobs placing themselves in what Ryan and Haslam (2005) describe as precarious positions. Visibility places women in a more powerful position, but risks greater exposure and ridicule if they fail. By raising their profile, a candidate becomes more noticeable to the senior ranks, thus identifying themselves and making connections with them endorsing Linehan's (2001) view that it is 'who' not 'what' you know that may influence success at a promotion board. One officer commented that:

Nepotism is alive and well.

The promotion systems superficially appear to be fair and based upon competence but it does seem that there are some incidents when nepotistic behaviours are exhibited.

\section{Networking}

The ability to successfully network positively impacts upon career progression. The establishment of formal/informal networks, role models, and mentors are essential elements of working life. All of the participating forces in this study had access to both national, inter, and intra force female networks, such as the British Association of Women in Policing (BAWP) and the Senior Women in Policing conferences. Forces tend to have their own internal women's support networks to which women may subscribe as well as the National Police Federation that serves to represent all rank and file officers. The validity of the women's networks appeared variable according to individual experiences, with some valuing them highly with others dismissing 
them as unprofessional due to their social content. Linehan's (2001) 'old boy's networks' that frequently include sporting and social activities which are a positive influence in men's careers seems to have negative connotations when applied to female networks. There appears to be a dichotomy between the male and female perception of networking. Women appear reluctant to engage in female social activity due to a fear of males interpreting such activity as being a sign of weakness rather than the strength and power of being feminine (Baxter, 2003). One Chief Officer commented positively in relation to the Senior Women's network stating it was:

A good network that combines both support and encouragement with a capacity to influence strategy and policy at a national level.

Not all such networks are perceived as powerful and helpful and can be regarded by both males and females as divisive. Some women objected to being automatically included in an all-female network. Some perceive the networks as being a powerful opportunity for mutual peer support, but this tended to be those at the lower ranks. Senior ranking women commented upon their inability to engage widely with formal networks due to work commitments and that is sometimes assumed to be apathy by the lower ranks.

Due to the nature of police work there are frequently difficulties associated with policies and practices that are adopted by civilian employers, particularly those in relation to part time working, maternity, and paternity policies along with other good HR practices such as return to work. At the lower ranks the opportunity to work flexibly is limited due to the nature of the shift systems and 365 days per annum 24/7 hours' demand. Senior ranks have some opportunities and powers to undertake a more flexible approach to planning their workload.

The lack of female role models negatively influences the numbers who aspire to the senior ranks. There are accounts that those who have preceded aspirational officers have exacerbated the issue by "pulling up the ladders behind them". The majority of the senior women that participated in this study expressed a desire, even a duty to support and nurture those who aspired to the senior ranks. One officer recognized this by stating:

They've (Chief Officers) got an incredible workload. It must be difficult to fit everything in.

It is interesting to note that all of the participants in this study expressed the importance of being recognized and valued for being female, for contributing to changing the male perspective of policing. They recognize they are pioneers, to an extent, in an organization that has a gradually shifting deep rooted culture altering the power relations within it.

\section{Discussion}

The establishment of effective and powerful relationships and networks can significantly and positively influence women's ability to progress. Early career officers are faced with difficulties relating to the promotion and shift systems, with more senior ranking officers facing equally difficult, yet different challenges in relation to promotion. This paper focuses upon more senior ranks where the opportunity to utilize role model or mentoring relationships effectively can reap rewards.

The importance of mentoring as a development tool is well documented alongside access to influential role models providing examples of internal custom and practice within specific 
settings. Mains and MacLean (2017), for example, acknowledge and express the importance of mentoring in organizations that are experiencing significant change. They suggest that mentoring one to one, group or peer mentoring as a strategic HRD intervention allows individual and organizational growth that is responsive to the environment in which a particular organization operates providing aspiring individuals with opportunity for guidance, support, and networking likely to enhance their career trajectories. They imply that utilizing other organizations' mentoring schemes can, in some circumstances, prove beneficial, especially if the two organizations have some degree of synergy.

Sheerin and Hughes (2018) identify the importance of access to networks in order to tailor and develop support mechanisms particularly for women in male-dominated organizations. They comment upon the differences in ability to access networks when the lens of gender is applied, commenting upon the continued existence of male networks that are exclusionary to women. They also extol networking as a recognized tool in continuous professional development. Specifically within UK policing Astley (2018, p. 68) identifies that "the subtleties of establishing strong networks and mentors enabling individuals to gain greater access to more equal opportunity in terms of career progression can prove significant".

Once officers have reached the level of Inspector or above, the importance of a mentor or champion is a significant factor in their ability to succeed (Ramaswami et al., 2010). Without the support and recommendation of another senior officer, regardless of gender, the ability of an individual to attain the next rank appears limited. In order to move into a senior or politically significant role women need to be associated with a powerful supporter. If not, they are frequently passed over, possibly as a result of their exclusion in the informal male networks where business still appears to be done. Wider society continues to perceive policing as predominantly male (Lord \& Friday, 2003; Rabe-Hemp, 2009). Without the establishment of a positive and powerful influencer it seems that the majority of female officers are destined to remain in the lower ranks resulting in a depletion of the talent pool that exists within the service.

The factors preventing women from achieving higher ranks relate to subtle factors, such as selfefficacy, sufficiency of role models and mentoring opportunities combined with the establishment of meaningful networks. Ramaswami et al. (2010) and Archbold and Moses-Schulz (2008) consider that mentoring and networking are generally controlled by males and those that have access to male mentors are more likely to achieve success. Women appear to desire to be mentored by their own kind, regardless of the evidence suggested by such authors. The limited numbers of powerful and influential female mentors appears to have a detrimental effect upon the numbers of females that achieve the senior ranks. By enabling access to female mentors, possibly from other associated agencies, such as the Prison Service, Ambulance Service or other associated contributors to the criminal justice sector, improvement in female representation may occur.

The role of networks seems to be less effective the higher the rank of officer, resulting in their isolation due to their lack of numerical representation. The impact is that the senior ranks appear unattractive to the majority of female officers who choose to exercise their power to control their own destiny within a male-dominated service. Women define their careers by making life choices based upon family circumstances, values and beliefs. Senior officers appear to recognize the need to mentor and nurture talent, but the ability to provide gender matched mentoring is impossible due to the minority representation of females in senior roles. It seems that by encouraging lower ranking females to view senior women as role models, but accepting senior 
male officers as mentors might provide some solution. Lessons might be learnt from the strategy of the College of Policing where direct entry to Inspector and Superintendent requires candidates to be assigned on a rotational programme to work with colleagues with specific expertise in order for them to gain experience. Effectively assigning them a series of mentors.

Power and positive relationships are key aspects of addressing the gender imbalance in policing. Policymakers can improve and unleash the potential of the workforce by accommodating shifts in cultural attitudes. The adoption of good working practices and policies adapted from examples of good HR practice from the civilian world is recommended. Workforce and workload planning are key elements of this shift in culture along with a recognition that some of the barriers to women's career progression have been overcome by other organizations by inter-agency working. The lack of mentors might be addressed by working with other organizations within the criminal justice sector and indeed other public sector organizations offering blue light services as suggested by Mains and MacLean (2017). Access to strong and positive mentoring relationships will enable women to reach their potential, reducing wasted talent by containing women to the lower ranks and address the gender imbalance. An example of this is Advance HE which delivers the Athena Swan initiative in the education sector championing the equality and diversity of staff focusing upon developing women as leaders. This could be a model that the service could consider adopting.

\section{Conclusion}

Organizational attempts to improve flexible working practices and efforts to attract more females to the service diminish with rank. Women who choose to adopt more family friendly working practices in policing do so knowing that they are likely to be sacrificing their long-term careers (in terms of gaining rank) and so remain within the lower ranks. Senior officers hold a significant and powerful key to unlocking the dearth of female representation in the future by changing cultural attitudes towards more flexible approaches to work and the notion of commitment. They need to encourage female officers to progress their careers and providing a structured basis for them to do so.

In order to share the pockets of good practice that exist within individual forces and the existing opportunities for mutual female support, such as BAWP and other female networks, HRD professionals within the service can endorse the benefits of accessing networks. Furthermore, they can ensure that existing senior ranking women are actively involved and visible in such networks which enables lower ranks to gain access to senior officers in less formal situations.

A further consideration is for all senior ranking officers to be trained to be coach/mentors as part of their role and that this activity to become the norm, rather than an over-reliance on the willingness of individual senior officers who make personal sacrifices to adopt coach/mentor roles to develop up and coming officers. Coach/mentor training should be incorporated into the senior leadership programme and be regarded as a necessary function of Chief Officers enabling the perpetuation of talent recognition and succession planning in forces. The practice of embedding such activity into the performance development review system of all senior ranks would be relatively easy to implement with limited cost implications. Recognition by the service that such practices are a vital element to the successful development of all aspirational officers, regardless of gender, is essential. Investing in talented individuals will naturally redress the gender imbalance in the medium to long term. 


\section{References}

Astley, J. (2011). Women in Policing: Why so few achieve the ACPO ranks, PhD Thesis, University of Liverpool, Liverpool.

Astley, J. (2018). Conflicts and Challenges of Gender in the Workplace: The Police Service in England, Wales and Northern Ireland. In Hidden Inequalities in the Workplace, pp. 67-90, Palgrave MacMillan

Archbold, C.A., \& Moses-Schulz, D. (2008). Making Rank: The lingering effects of tokenism on female police officers promotion aspirations, Police Quarterly, 11(1), 50-73.

Baxter, J. (2003). Positioning gender in discourse: A feminist methodology, Basingstoke, Palgrave MacMillan.

Butler, J. (2004). Undoing gender, Abingdon, Routledge.

Campbell, E. (2003). Interviewing men in uniform: A feminist approach, Social Research Methodology, 6(4), 285-304.

Collinson, D. L. (2003). Identities and insecurities: Selves at work, Organization, 10(3), 527-547.

Cordano, M., Scherer, R. F., \& Owen, C. L. (2002). Attitudes toward women as managers: Sex versus culture, Women in Management Review, 17(2), 51-60.

Dhunpath, R. (2000), Life-history methodology: "Narradigm” regained, Qualitative Studies in Education, 13(5), 543-551.

Dick, P., \& Jankowicz, D. (2001). A social constructionist account of police culture and its influence on the representation and progression of female officers, Policing. An International Journal of Police Strategies and Management, 24(2), 181-199.

Hargreaves, J., Husband, H., \& Linehan, C. (2017). Police workforce, England and Wales, 31 March 2017, Home Office Statistical Bulletin 10/17, London, Home Office.

Hargreaves, J., Husband, H., \& Linehan, C. (2018). Police workforce, England and Wales, 31 March 2017, Home Office Statistical Bulletin 11/18, London, Home Office.

Kitzinger, C. (2000). Doing feminist conversation analysis, Feminism and Psychology, Vol 10(2), 163-193.

Linehan, M. (2001). Networking for female managers' career development, Journal of Management Development, 20(10), 823-829.

Lord, V. V., \& Friday, P. C. (2003). Choosing a career in police work: A comparative study between applicants for employment with a large police department and public high school students, Police, Practice and Research, 4(1), 63-78.

Mains, I., \& MacLean, S. (2017). Developing across boundaries - mentor and mentee perceptions and experiences of cross-organisational mentoring, Industrial and Commercial Training, 49(4), 189-198.

Martin, S. E. (1979). POLICEwomen and PoliceWOMEN: Occupational role dilemmas and choices of female officers, Journal of Police Science and Administration, 7(3), 314-322.

Mavin, S. (2006a). Venus envy: Problematizing solidarity behaviour and queen bees, Women in Management Review, 21(4), 264-276.

Mavin, S. (2006b). Venus envy 2: Sisterhood, queen bees and female misogyny in management, Women in Management Review, 21(5), 349-364.

Mavin, S. (2008). Queen Bees, wannabees and afraid to bees: No more 'best enemies' for women in management, British Journal of Management, 19, 75-84.

Mavin S., Grandy G., \& Williams J. (2014). Experiences of Women Elite Leaders Doing Gender: Intragender Micro-violence between Women, British Journal of Management, 25(3), 439-455.

Metcalfe, B. D. (2008). A feminist post-structural analysis of HRD: Why bodies, power and reflexivity matter, Human Resources Development International, 11(5), 447-463.

Mellick, M., \& Fleming, S. (2010). Personal narrative and ethics of disclosure: A case study from elite sport, Qualitative Research, 10(3), 299-314.

Muller-Hendryk, R., (2019). Double standards stunting female career progression, HR Magazine, London, https://www.hrmagazine.co.uk/article-details/double-standards-stunting-female-career-progression (Accessed 26/02/19).

Musson, G. (2006). Essential guide to qualitative methods in organizational research, Edited by Cassell, C. and Symon, G., London, Sage. 
O'Connor, V. (2001). Women and men in management - a "different needs" hypothesis, Women in Management Review, 16(8), 400-404.

Olsson, S. (2000). Acknowledging the female archetype: Women managers' narratives of gender, Women in Management Review, 15(5/6), 296-302.

Osterlinde, M., \& Haake, U. (2010). The leadership discourse amongst female police leaders in Sweden, Advancing Women in Leadership Journal, 30(16), 1-24.

Rabe-Hemp, C. E. (2009). POLICE women or policewomen? Doing gender and police work, Feminist Criminology, 4(2), 114-129.

Ramaswami, A., Dreher, G. F, Bretz, R., \& Weithoff, C. (2010).“Gender, mentoring and career success: The importance of organizational context, Women in Management Review, 63(2), 385-405.

Ryan, M. K., \& Haslam, S. A. (2005). The glass cliff: Evidence that women are over-represented in precarious leadership positions, British Journal of Management, 16, 81-90.

Sandino, L. (2007). Relating process: Accounts of influence in the life-history interview, Journal of Visual Arts Practice, 6(3), 191-199.

Sealy, R. H. V., \& Singh, V. (2010). The Importance of Role Models and Demographic Context for Senior Women's Work Identity Development, International Journal of Management Reviews. Sep 2010, 12(3), 284-300.

Sheerin, C., \& Hughes, C. (2018). Gender-segregated work spaces and social capital - does context matter? European Journal of Training \& Development, 42(3/4), 226-245.

Silvestri M., \& Crowther-Dowey, C. (2008). Gender \& Crime: Key approaches to criminology, London, Sage.

Stokoe, E. H., \& Smithson, J. (2001). Making gender relevant: Conversation analysis and gender categories in action, Discourse and Society, 12(2), 243-269.

Wodak, R. (1997). Introduction: Some issues in gender and discourse in Gender and Discourse Ed. Wodak, R., London, Sage.

\section{The Author}

Dr Janet Astley is a Principal Lecturer in Leeds Business School within the subject group of Leadership, Governance, and People Management at Leeds Beckett University. Her research interests specifically relate to senior female career progression and diversity in policing. The aim of her research is to engender a more diverse workforce with ethical approaches to the deployment of officers by the implementation of policies and practices established at both local and national levels based upon sound HR practices. Before her academic career her previous experience was gained in HRM and training within public sector organizations and policing. 